\title{
Inception and Insights of Interactive Vertical Integrated Teaching for Undergraduates in Medical Curriculum
}

\author{
Nagarkar Rajhans Kishanrao* \\ Department of Microbiology, Medical Education Unit (MEU) Coordinator, \\ ESIC Medical College, Gulbarga, India \\ *Corresponding author
}

\section{Keywords}

Insights, Vertical

Integrated

Teaching,

Interactive teaching

learning methods,

Medical Curriculum

Article Info

Accepted:

12 February 2019

Available Online:

10 March 2019

\section{A B S T R A C T}

Integrated teaching links the basic sciences and clinical subjects to get in depth knowledge. It is exciting and motivates learning. This study was conducted to know the insights of integrated teaching and learning experiences of students in medical curriculum. A prospective qualitative study was conducted involving 64 participants through purposive sampling. After ethical clearance students were briefed about integrated teaching and project. Topic based interactive vertically integrated module was prepared by involving faculty of Microbiology, Pathology, Preventive and Social Medicine, Pulmonary medicine and general Medicine. Interactive teaching learning methods like picture prompt, interactive video, group test and MCQ were included in the module. Pre validated questionnaire was used to obtain feedback from students which included closed ended (on likert scale) and few open ended questions. Data from questionnaire was compiled and analysed. $60.94 \%$ students strongly agreed that integrated teaching linked basic sciences and clinical subjects. Among interactive teaching learning methods, interactive videos helped to a greater extent followed by MCQ, picture prompt and group test. $37.50 \%$ students expressed there was improvement in overall knowledge related to topic due to integration. $37.50 \%$ participants wanted repetition of integrated teaching once in a month. Integrated teaching proved to be intriguing and involving for students. The study showed students were having positive attitude towards integrated teaching.

\section{Introduction}

Integration is an act of combining which is necessary to the completeness of whole. As per vision 2015 document of Medical Council of India, new curriculum for MBBS students aims to integrate different disciplines. Horizontal and vertical integration in medical education helps to create a knowledge base relevant to clinical practice. Integration across disciplines but within a finite period of time is horizontal integration.

Vertical integration is across time which disrupts the barrier between basic \& clinical subjects. Many countries all over the world are adopting and carrying out integrated curriculum in medical colleges. Integrated 
teaching (IT) makes teaching exciting. It also helps students to take control of their own learning (1-3).

Traditional teaching makes topic disconnected from other subjects and material related to other specialities is also taught by corresponding teacher only (4-6). Due to this in depth understanding of topic doesn't occur. Integrated teaching helps in correlation and links basic sciences with clinical subjects which facilitates increase grasp of medical principles. Aim of this study was to introduce and implement vertical integrated teaching (79).

The main objectives of this study to know the insights of students on topic based interactive vertical integrated teaching module. And also to asses learning experience of the students.

\section{Materials and Methods}

A prospective study was conducted at EISC Medical College, Gulbarga. Purposive sampling was done and 64 participants participated in study. Approval from Institutional Ethical Committee obtained and informed consent was taken from participants. Students were given brief introduction of interactive vertical integrated teaching, purpose, nature and time required. Topic based interactive vertical integrated module on tuberculosis was prepared. Departments involved were Pathology, Pharmacology, Microbiology, Preventive and Social Medicine (PSM), General Medicine \& Pulmonary Medicine. Before finalizing the module each faculty discussed how to avoid repetitions.

Different interactive teaching learning (TL) methods like picture prompt, interactive video, group test and multiple choice questions (MCQs) included in the module. One day schedule of four and half hours (10-1 pm \& 2:30-4 pm) decided and declared.
To know the students learning experience and feedback, close ended and open ended questionnaire was prepared. 5 point likert scale used to take feedback for close ended questionnaire. For experience of learning about teaching learning methods 3 point likert scale was used. Again 5 point likert scale was used to evaluate program. Proper instructions were given to students to fill feedback sheets.

\section{Results and Discussion}

WHO also supported student centred integrated teaching in medical curriculum. Integrated teaching gives a common platform to likeminded teachers who work as a team for students benefit. Due to interactive teaching students get actively involved and learning becomes effective.

Few of the students commented on time duration as prolonged. Similar finding was noted by Dr. Pruthvi et al., study. Few students commented integrated teaching was extremely interesting and they grasped enormous.

This was in line with study done by Raakhi Tripathi et al., Why integrated teaching is better was open ended question to which students gave different feedback. 37\% commented Integrated Teaching was better due to improvement in overall knowledge.

According $25 \%$ participants, Integrated Teaching gave better understanding.

Other 25\% participants mentioned interactive Teaching Learning methods were the reason for liking Integrated Teaching. 4\% participants felt Integrated Teaching was interesting, interactive videos made procedural skills to remember. Other $4 \%$ students felt it was good example of team work. A limitation of our study was insights of faculty members not taken

(Graph

$1-4)$. 
Graph.1

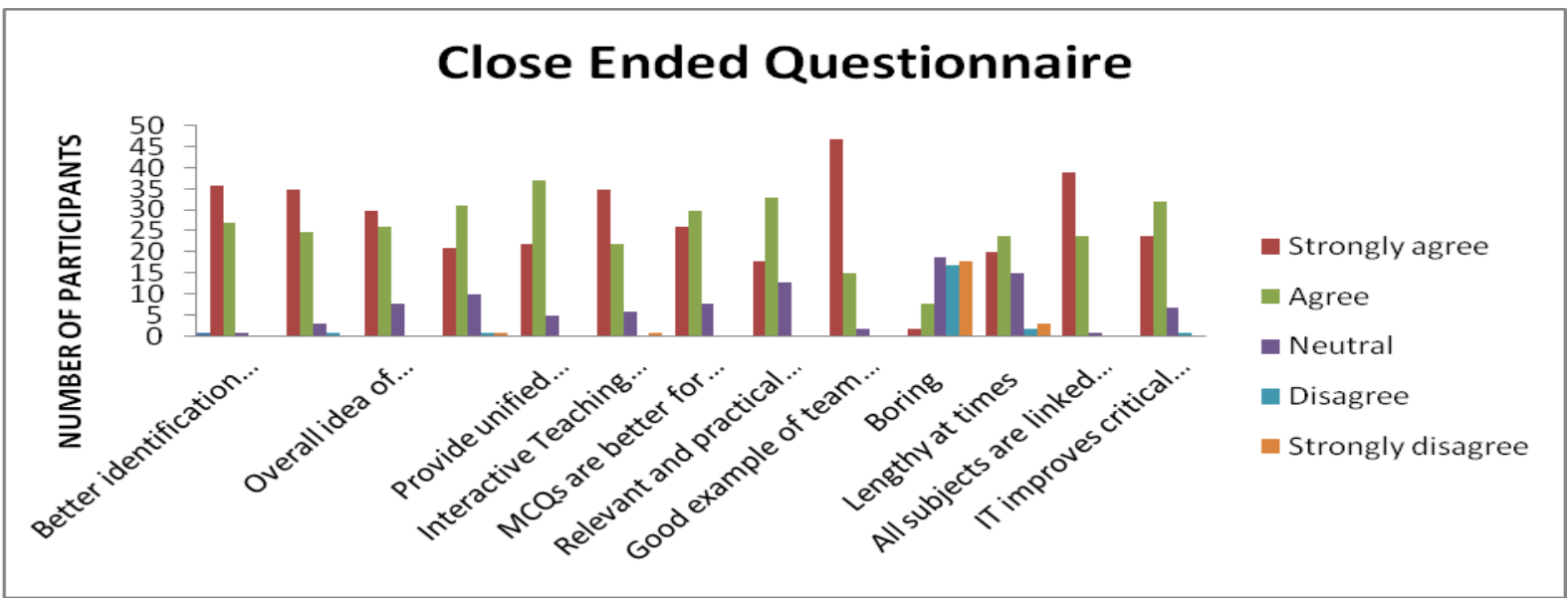

Graph.2

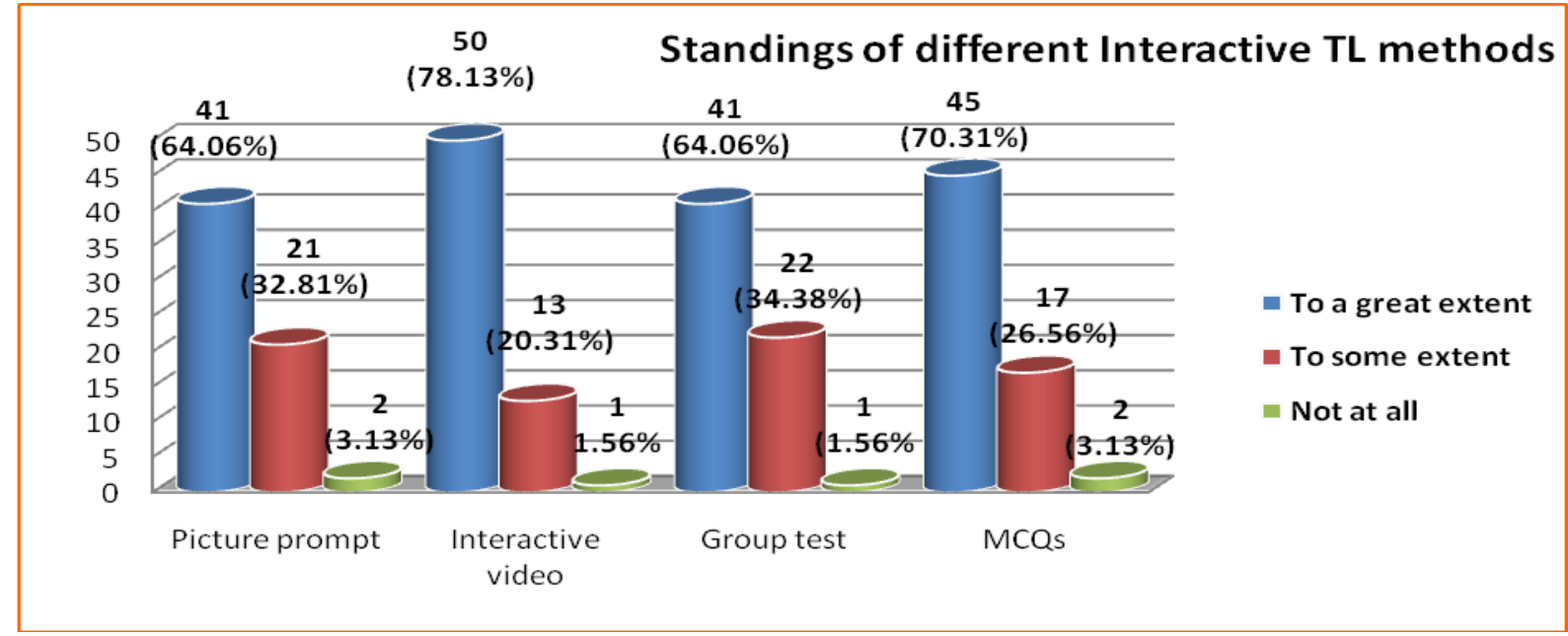

Graph.3

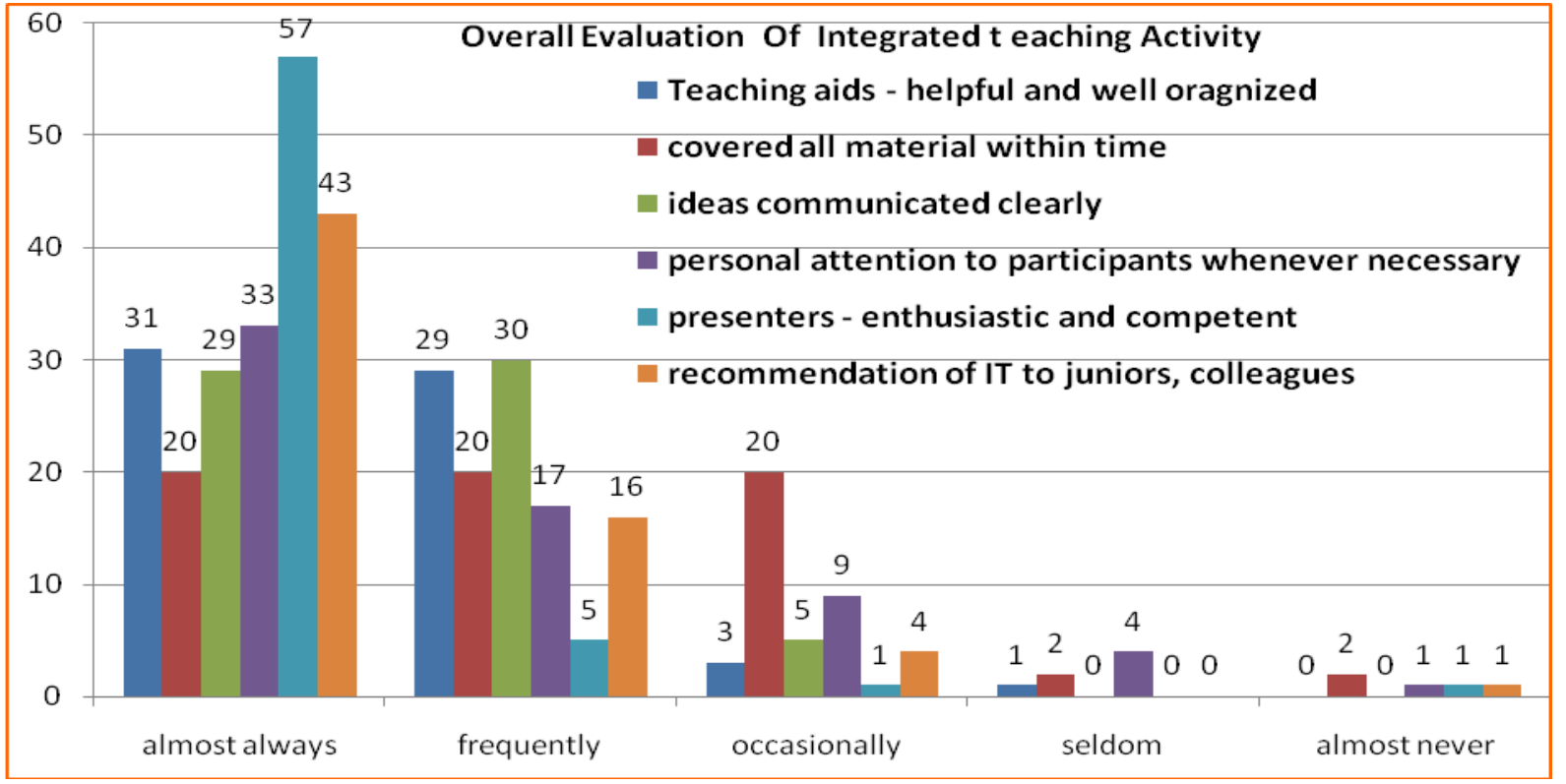




\section{Graph.4}

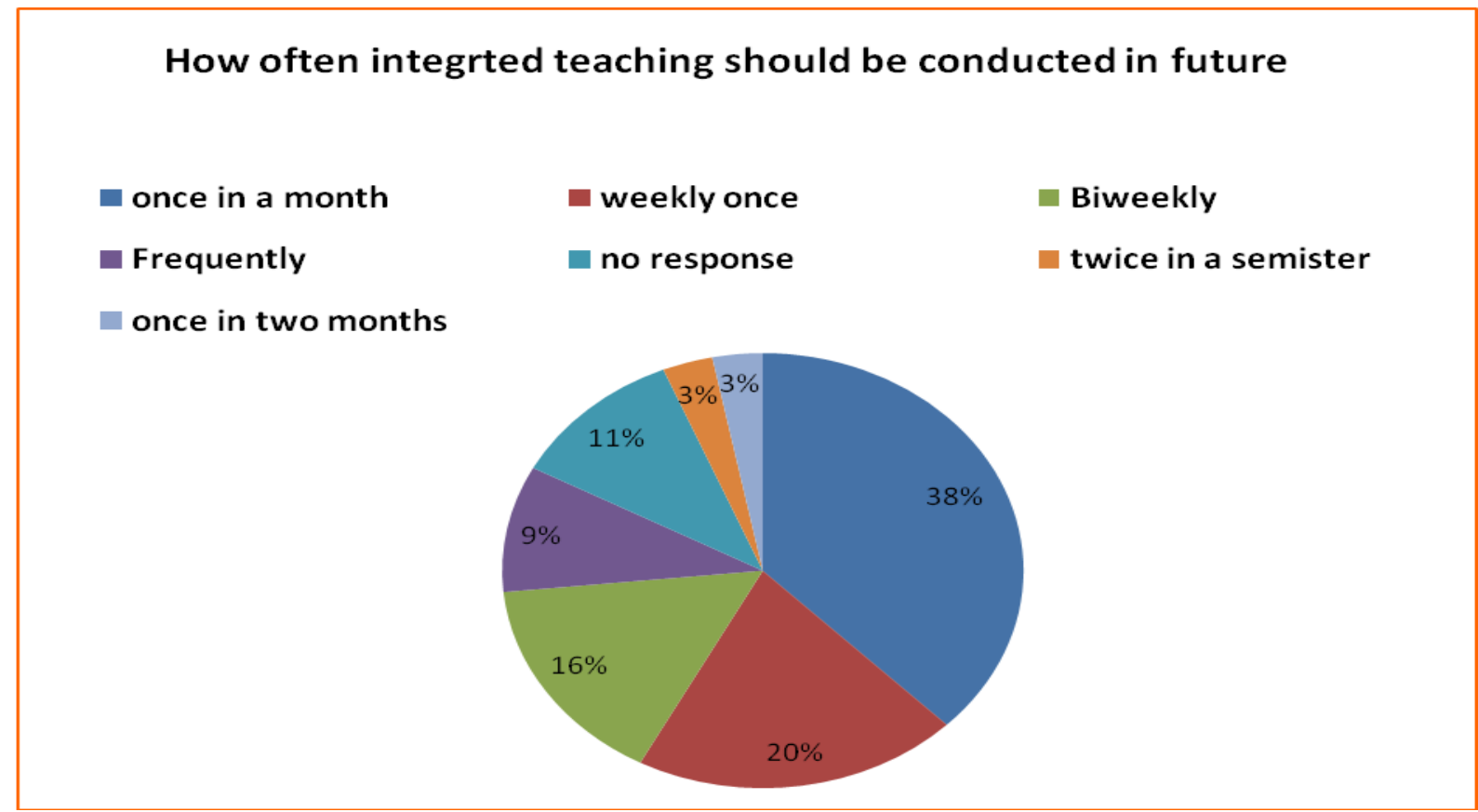

In conclusion, students showed a positive viewpoint towards integrated teaching. With interactive teaching learning methods, learning became intriguing and involving for students. Linking of basic sciences with clinical subjects through topic based module gave overall knowledge of the topic to students.

\section{Acknowledgement}

Dr. M. R. Chandrashekhar, Dr. A. L. Nagaraja, Dr. H. S. Kadlimatti, Dr. Sachin, Dr. Suraj, Dr. Lavanya Peter, Dr. Poonam Shingade, Dr. Nilesh Kate, Dr. Pramod Kumar \& all the faculties of DOME, Nodal centre, JNMC, Belagavi, Karnataka.

\section{References}

1. Sarmishtha Ghosh et al., Implementation of integrated learning program in neurosciences during first year of traditional medical course: perception of students and faculty. BMC Medical Education, 2008, 8:44.
2. Dr. Madhuri S. Kate et al., Introducing Integrated Teaching in Undergraduate Medical Curriculum, International Journal of Pharma Sciences and Research (IJPSR), Vol. 1(1), 2010, 1822

3. Pruthvi D et al., Integrated teaching Students Perspective. J Educational Res \& Med Teach, 2013;1(1):37-9

4. Tripathi $\mathrm{R}$ et al., Introduction of Integrated lecture module: performance and perception of II year medical students. Int J Pharmacol and Clin Sci, 2013;2:47-54

5. Dr. Swati Shah et al., Introduction of integrated teaching in I MBBS: perspective of students. IJBAP, 2014; 3(1): 352.

6. Dr. Prafull Kamble et al., IJSR International Journal Of Scientific Research, Vol: 3, Issue: 9 September 2014.

7. Kaliaperumal Karthikeyan et al., Integrated modular teaching in undergraduate medicine. The National 
Medical Journal of India 2014; VOL. 27, NO. 2, 90-94.

8. Dr. Prasad Uma et al., Student's perception about integrated teaching in an undergraduate medical curriculum. IJBAMR, March 2015, 4(2): 77-52.
9. Anshu Gupta et al., Implementation of Interactive Teaching Learning Methods in large Group in Endocrine Pharmacology Indian Journal of Pharmacy and Pharmacology, OctoberDecember 2015; 2(4): 197-202.

\section{How to cite this article:}

Nagarkar Rajhans Kishanrao. 2019. Inception and Insights of Interactive Vertical Integrated Teaching for Undergraduates in Medical Curriculum. Int.J.Curr.Microbiol.App.Sci. 8(03): 1592-1596. doi: https://doi.org/10.20546/ijcmas.2019.803.185 